EPJ Web of Conferences 59, 03014 (2013)

DOI: $10.1051 /$ epjconf/20135903014

(C) Owned by the authors, published by EDP Sciences, 2013

\title{
Laser study into and explanation of the direct-indirect target concept
}

\author{
N.G. Borisenko1,a , S. Chaurasia ${ }^{2}$, L.J. Dhareshwar², A.I. Gromov ${ }^{1}$, \\ N.K. Gupta ${ }^{2}$, P. Leshma ${ }^{2}$, D.S. Munda ${ }^{2}$, A.S. Orekhov ${ }^{1}$, S. Tripathi ${ }^{2}$ \\ and Yu.A. Merkuliev ${ }^{1}$ \\ ${ }^{1}$ P. N. Lebedev Physical Institute (LPI), Leninskiy pr. 53, Moscow 119991, Russia \\ ${ }^{2}$ Bhabha Atomic Research Centre (BARC), Mumbai-85, India
}

\begin{abstract}
The idea of direct-indirect target is experimentally tested with planar targets from LPI made of low-density metal foam (nanosnow) or of nanoparticles (30\%) in plastic aerogels. The laser experiments in BARC have shown that compared to plain targets the foams of/with nanoparticles demonstrate: 1) better $\mathrm{x}$-ray emissivity ; 2) smoother energy distribution over the target surface; 3 ) material flow from low-density wall being slower and more uniform; 4) active transverse energy transport over the target plane. These properties could be useful for hohlraums and direct-indirect concept.
\end{abstract}

\section{DIRECT-INDIRECT TARGETS SCHEMES}

Plasma from foams has been studied for decades [1 and ref.], but $\mathrm{Au}$ and Bi are not studied enough. The design of direct-indirect target using a $0.25 \mu \mathrm{m}$-thick outer gold shell was suggested in [2]. The advantage of this design was in the easy process of laser focusing. Disadvantages, such as low x-ray efficiency, necessity of short laser pulse duration and high velocity of Au-plasma were consequent.

Another design shown in Fig. 1 was proposed by Yu.A. Merkul'ev [3]. This is a target with Au-lowdensity converter which allows easy laser focusing and long laser pulse. As the result, the Au-plasma motion is slower, but the x-ray efficiency is still low. One more design, shown in Fig. 2, was proposed in [4]. The target with low-density absorber-converter was invented for $2 \mathrm{MJ} 5 \mathrm{~ns}$ laser pulses. Easy laser focusing, possibility of long laser pulse and high efficiency for $0.53 \mu \mathrm{m}$ wavelength are among its advantages. However with mixed interaction (both x-ray and thermal) taking place in this case, the cryogenic DT layer is difficult to keep.

M.D. Rosen and J.H. Hammer proved [5], and observed experimentally [6], that X-ray temperature in gold low-density converter is higher than in ordinary Au-converter of indirect-drive targets.

$\mathrm{Au}$ low-density converters of heavy ions energy to $\mathrm{x}$-rays should have their density varying from $10 \mathrm{mg} / \mathrm{cm}^{3}$ to $400 \mathrm{mg} / \mathrm{cm}^{3}$ [7]. Unlike polymers, metal foams are heat conductive and allow cryo-layer formation in fuel capsule of the target by rapid cooling (quench).

Low-density $A u$ is being developed in LLNL and GA, USA, as well as in LPI (Russia).

\section{METAL FOAMS PRODUCTION FOR DIFFERENT DENSITIES}

No universal fabrication methods exist for high-Z low-density metals in a wide density range. Various technology routes of metal low-density layers are realized for $\mathrm{Cu}, \mathrm{Sn}, \mathrm{Sn}+\mathrm{Mo}, \mathrm{Bi}, \mathrm{W}, \mathrm{Bi}+\mathrm{W}, \mathrm{Au}$, $\mathrm{Au}+\mathrm{W}$.

\footnotetext{
ae-mail: ngbor@sci.lebedev.ru
}

This is an Open Access article distributed under the terms of the Creative Commons Attribution License 2.0, which permits unrestricted use, distribution, and reproduction in any medium, provided the original work is properly cited. 


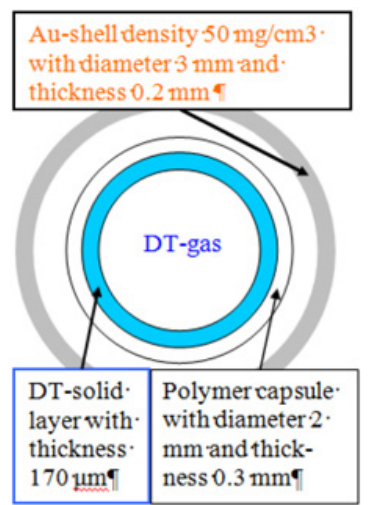

Figure 1. Design of target with Au-low-density absorber-converter.

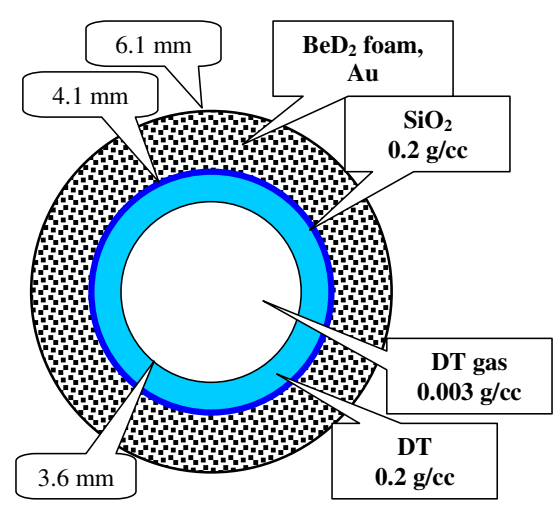

Figure 2. Design of target with low-density absorber-converter for $2 \mathrm{MJ}$.

For the direct-indirect scheme, target structure is essential: solid elements of $<0.3$ micron, pores $<10$ micron are needed for rapid homogenization at temperatures $100 \mathrm{eV}$ and higher.

We produce metal low-density layers of $\mathrm{Bi}$ or $\mathrm{Au}$ at $50-300 \mathrm{mg} / \mathrm{cc}$ with pore sizes less than 20 microns, solid elements - chains of metal nanoparticles $100 \mathrm{~nm}$ in diameter. Subsequent thermal treatment and pressing result in layers $0.2-4 \mathrm{~g} / \mathrm{cc}$, pores being twice or 2.5 times less, average particle size enhanced to $150-200 \mathrm{~nm}$. Metal densities less than $100 \mathrm{mg} / \mathrm{cc}$ (down to $10 \mathrm{mg} / \mathrm{cc}$ ) are obtained in a composite of heavy metal nanoparticles $50-100 \mathrm{~nm}$ inside polymer network with solid fibers of 0.1 micron size and 3 micron apart.

Metal nanoparticles and foam layers are fabricated inside a special setup according to a widely used technique of cooled smog precipitation in inert gas (pure nitrogen, argon or helium) [8,9]. Heater gives dense atomic metal flow. Metal nano-snow from nanoparticles is obtained inside a 1.5 meter high chamber in $1-5 \mathrm{~mm} \mathrm{Hg}$ gas-pressure [10]. Nanoparticle size depends on pressure and gas composition, thus He-surroundings result in tiny particles and lower densities. The optimum pressure for densities less than $1 / 100$ of the solid ones is found to be $150-700$ Torr.

\section{METAL FOAM STRUCTURE AND CHARACTERIZATION}

Hot metal is evaporated within several minutes ( 3 to 20 ) whereas sedimentation lasts 16-48 hours. What's then? Nanoparticles or globules?

We expect they are globular, thus forming fractal layers (Fig. 3), their structure being self-similar at different scale (say, 10-20 microns and 200-400 microns).

SEM diagnostics is destructive for the studied sample. After coating with $40-100 \mathrm{~nm}$ conductive gold, the metal nanoparticles look coarser and thicker than they really are. Figure 3 shows pores of 1-10 micron characteristic sizes for layers of globules, and nanoparticles forming chains. Combinations are likely: nano-snow formation with subsequent tiny particles prolonged sedimentation. The surface does not become even, high relief is possible, which may be caused by differing electric charges of the sample and of nanoparticles falling.

The main working layer of $\mathrm{Bi}$ is deposited onto a plastic film of $0.2-0.3$ micron thickness. Interference colors give estimation of the thickness, measured more accurately by an optical profilometer. The foil is glued to an $8 \mathrm{~mm}$ diameter washer with opening of $2.5 \mathrm{~mm}$. A 1-2 mm slit may be made for plasma dynamics observations and energy transport studies with $\mathrm{x}$-ray streak-camera. 


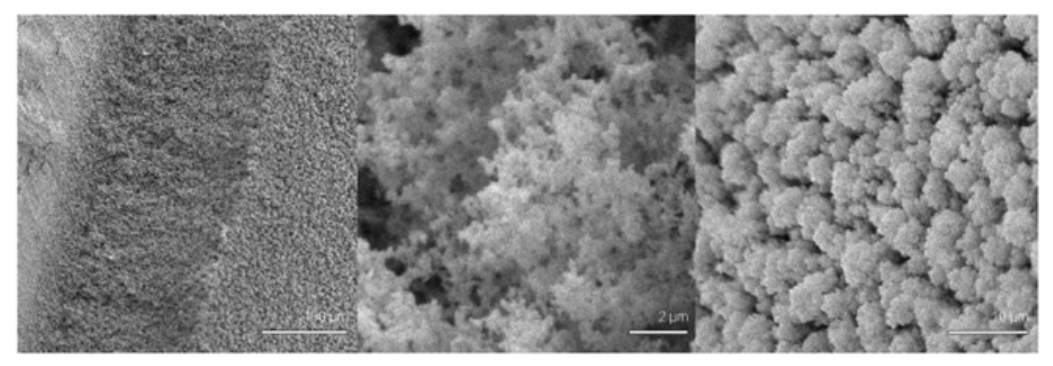

Figure 3. SEM images of (left) $\mathrm{Sn}+$ Mo nanoparticle layer cut (scale $100 \mu \mathrm{m}$ ); (center) Bi at density $0.1 \mathrm{~g} / \mathrm{cc}$ (scale $2 \mu \mathrm{m}$ ); (right) Bi surface. Globular structure is visualized with characteristic sizes of 3-8 micron (scale $10 \mu \mathrm{m}$ ).

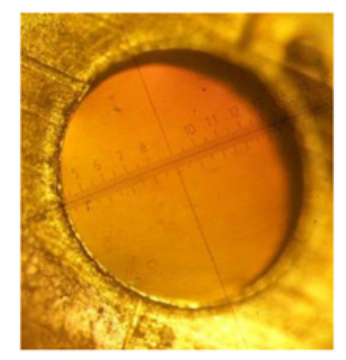

Figure 4. Laser target photo.

Each target is fabricated together with a pilot sample for further monitoring and processing to obtain foam parameters [9].

\section{EXPERIMENTAL SETUP: LASER AND DIAGNOSTICS}

The target was illuminated with the fundamental wavelength of a Nd-glass laser, over a focal spot of $100 \mu \mathrm{m}$. A high power $0.5 \mathrm{~ns}$ laser pulse with intensity of the order of $10^{13}$ to $2 \times 10^{14} \mathrm{~W} / \mathrm{cm}^{2}$ was focused with an f/5 lens in a chamber evacuated to $4 \times 10^{-5}$ mbar. For energy balance measurement three calorimeters were used. The first one calibrated the incident laser light energy, another one measured front scattered light from target and the third one at the target back side measured transmitted laser energy. Five x-ray diodes covered with various x-ray transmission filters were installed on the front side of the target. For X-ray measurement, the AXUV detector cover with B10 filter (transmission $>0.9 \mathrm{keV}), 5 \mu \mathrm{m}$ Nickel filter and $20 \mu \mathrm{m}$ Aluminum filter was placed at $\left(45^{\circ}, 0^{\circ}\right)$ and at a distance of $65 \mathrm{~cm}$. The detector covered with $5 \mu \mathrm{m} \mathrm{Al} \mathrm{filter} \mathrm{(transmission} \mathrm{over} 0.8-1.56 \mathrm{keV}$ and $>2.4 \mathrm{keV}$ ) was placed at angle $\left(\theta=45^{\circ}, \varphi=55^{\circ}\right)$ to target normal direction at a distance of $40 \mathrm{~cm}$. The detector covered with $12 \mu \mathrm{m}$ Ti filter (transmission over $3-5 \mathrm{keV}$ ) was placed at $\left(45^{\circ}, 10^{\circ}\right.$ ) to target normal at a distance of $40.7 \mathrm{~cm}$. For the ion parameter measurements two ion collectors, at front ion collector FC1 placed at $\left(45^{\circ}, 35^{\circ}\right)$ with target normal at a distance of $54.7 \mathrm{~cm}$, and on the back, ion collector FC2 placed at $\left(45^{\circ}, 0^{\circ}\right)$ with target normal at a distance of $55 \mathrm{~cm}$. Shadowgrams presented below were done in green light. Different delays could be performed between the frames.

\section{EXPERIMENTAL RESULTS (METAL FOAM, NANOPARTICLES AND SOLID METAL)}

In the two experimental series (2009 and January-July 2010) reported earlier [11] and presently, 230 laser shots were done in total. The data was processed statistically. Each experimental point plotted is averaged over 3-4 to 10-12 laser shots. Here we provide results regarding Bi which are statistically very reliable, as each point is an average over 8 to 12 shots, giving 5\% experimental uncertainty.

Figure 5 shows emissivity spectrum that can be changed by additives (W). Figure 6 proved that soft $\mathrm{x}$-ray emission is higher if the foam is used.

The intensity of plasma $\mathrm{x}$-ray emission from low density polymer with $10 \% \mathrm{Cu}$ is $20-25 \%$ higher than the one from low density polymer without additives (Fig. 7). Transverse energy transport is more expressed in metal foam (Fig. 8, left) than in solid on the same scale (Fig. 8, right). From Fig. 8 left regular profile, the nanostructure initiated microturbulence is supposed. The foam layer flight can be compared by shadows on figure 9 . Laser light comes normally from the left. 


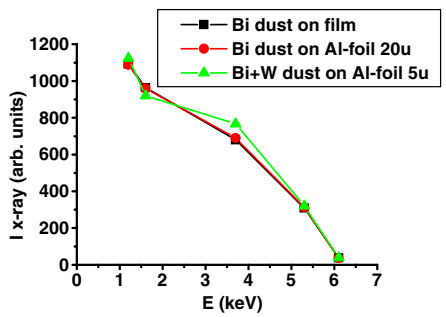

Figure 5. X-ray emission of $\mathrm{Bi}$ dust intensity on various substrates dependent on detector energy.

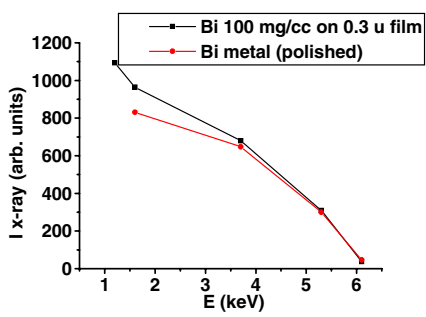

Figure 6. X-ray emission intensity of Bi-dust on polymer film and of Bi metal (polished) dependent on detector energy.

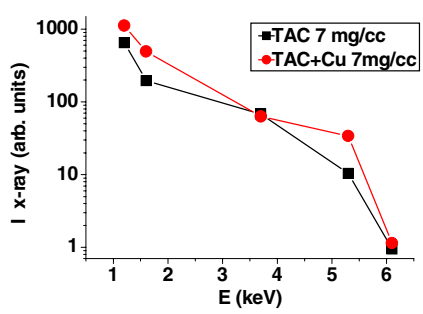

Figure 7. Adding the $\mathrm{Cu}$-nanoparticles results in higher $\mathrm{x}$-ray spectrum.

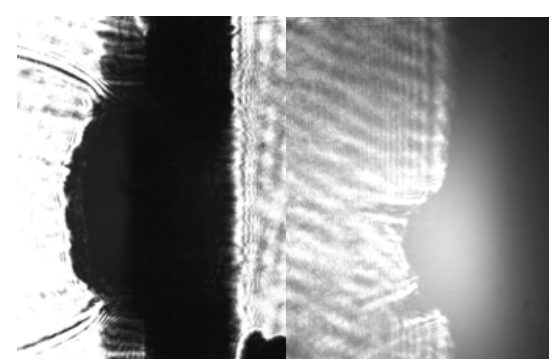

Figure 8. Shadowgrams (left) Bi-dust layer, density $100 \mathrm{mg} / \mathrm{cc}$, thickness $100 \mu \mathrm{m}$, (right) solid metal Bi.

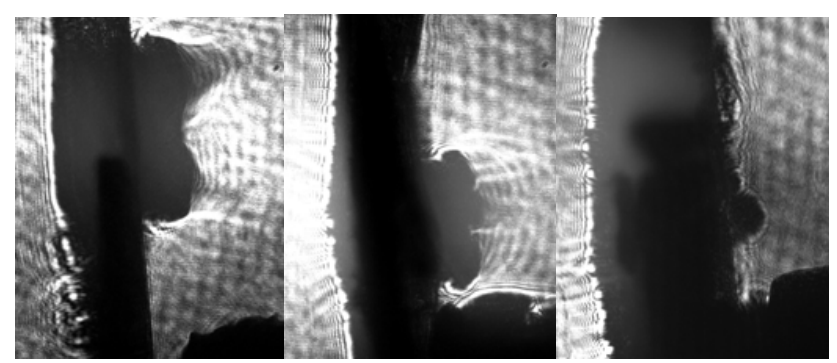

Figure 9. Shadowgrams (left) plastic foam target, density $2 \mathrm{mg} / \mathrm{cc}$, thickness $100 \mu \mathrm{m}$, delay $2.92 \mathrm{~ns}$; (center) Bi-dust layer, $\mathrm{E}_{\text {Laser }}=$ $9.9 \mathrm{~J}$, density $100 \mathrm{mg} / \mathrm{cc}$, thickness $30 \mu \mathrm{m}$, delay $4.8 \mathrm{~ns}$; (right) Bidust layer, $\mathrm{E}_{\mathrm{Laser}}=10.9 \mathrm{~J}$, density $100 \mathrm{mg} / \mathrm{cc}$, thickness $40 \mu \mathrm{m}$, delay $4.8 \mathrm{~ns}$.

\section{CONCLUSIONS}

The comparative experiments with metal targets show the differences in plasma behavior when foams are used. Low-density metal layers of nanoparticles with approximate density $100 \mathrm{mg} / \mathrm{cc}$ demonstrate features favorable for use in direct-indirect target designs.

1. The $\mathrm{x}$-ray spectra emitted by plasma of low-density $\mathrm{Bi}$ are more intense in the soft part than those from polished solid metal targets. Thin Bi layer is also a quite strong emitter.

2. The intensity of plasma $\mathrm{x}$-ray emission from low density $\mathrm{Bi}$ is $10-15 \%$ higher than that from solid polished Bi. The measurement accuracy is $5 \%$.

3. Plasma x-ray emission intensity from low-density Bi drops across the layer thickness growth. The effect is observed similarly when at the same polymer layer an Al-foil is used on its rear side.

4. $10 \%$ of $\mathrm{Cu}$ nanoparticles in a plastic foam result in up to $25 \%$ higher $\mathrm{x}$-ray yield.

5. Foam layer in-flight stability and smooth nearly-flat profile is observed, compared with solid.

6. Material flows from foam walls are slower and more uniform.

7. Active transverse energy transport is observed with nanoparticles in a thin foam layer.

\section{References}

[1] N.G. Borisenko, I.V. Akimova, A.I. Gromov et al. Journal de Physique IV 133, 305 (2006)

[2] E. Elieser, J. J. Honrubia, G. Velarg, Phys. Let. A 166, 249 (1992)

[3] Yu. A. Merkul'ev. Low-density absorber-converter of laser fusion target with direct laser beams irradiation. Report on Russian-China seminar, 29 March-3 April (1992) 


\section{IFSA 2011}

[4] S. Yu. Gus'kov, Yu. A. Merkul'ev, Quantum Electronics 31, N4, 311 (2001)

[5] M.D. Rosen, J.H. Hammer, Phys. Rev. E 72, 056403 (2005)

[6] P.E. Young, M.D. Rosen, J.H. Hammer et al., Phys. Rev. Let. 101, 035001 (2008)

[7] D.A. Callahan, M.C. Herrmann, M. Tabak, Laser and Particle Beams 20, 405 (2002)

[8] N.G. Borisenko, A.A. Akunets, A.M. Khalenkov et al., J. Russ. Laser Research 28, 500 (2007)

[9] L.A. Borisenko, A.S. Malikova, A.S. Orekhov. Image-processing of low-density metal nanoparticle layers (Bi) from the X-Ray tomograph SkyScan-1074. The 4th EMMI workshop on Plasma Physics with Intense Heavy Ion and Laser Beams, Darmstadt, 2-4 May (2011)

[10] A. M. Khalenkov, N. G. Borisenko et al., Laser and Particle Beams 24, 283 (2006)

[11] N. G. Borisenko, A. I. Gromov, A.S. Orekhov et al., Nanostructured targets irradiated with intense laser beams. The 4th EMMI workshop (see [9]) 